\title{
The Cultural Impact of Diffusion of IT Innovation in World Society
}

\author{
Maaruf Ali \\ School of Architecture, Computing and Engineering \\ University of East London \\ London, England, United Kingdom \\ m.ali3@uel.ac.uk maaruf@ieee.org
}

\author{
Mahdi H. Miraz \\ Dept. of Computer Science and Software Engineering \\ University of Ha'il; \\ Ha'il, Saudi Arabia; \\ Glyndwr University \\ Wrexham, Wales, UK \\ m.miraz@uoh.edu.sa
}

\begin{abstract}
A focused description of how culture affects the permeation of technology in world society is described in this paper including the use of diffusion of innovation theory. The factors tending to the diffusion of innovation are elucidated. It is concluded that sensitive adherence to culture is key in the opening of those more reserved societies to new innovative technologies.
\end{abstract}

Keywords- culture; IT; Innovation; World Society; Gompertz function, Bass model;

\section{INTRODUCTION}

The phenomena of how new technology including devices and gadgets that actually is up-taken in human society (both in organisations and by individuals) may be explained by the theory of "diffusion of innovations". This theory was first made famous by Prof. Everett M. Rogers, a professor of rural sociology, in his book titled, "Diffusion of Innovations", which was published as early as 1962 [1]. The book is currently in its fifth edition, last published in 2003[2]. A revised version, "Communication of Innovations; A CrossCultural Approach" [3], published in 1971, specifically addressed the effect of culture on how innovation spread through human society. Roger explains that diffusion is the process of how the news and uptake of innovation is communicated through social contacts and networks with respect to time. The background to this diffusion theory is diverse and quite multi-disciplinary. Roger identifies four factors that directly influence the rate of spread of an innovation, these being: "the innovation itself, [the] communication channels, time and a social system" [2]. Furthermore, the innovation must be financially supported and "widely adopted" for it to flourish and be self-sustaining. The new technology also has to reach a marker known as the "critical mass" in its rate of adoption. Five types of adopters were identified by Rogers, viz.: "innovators, early adopters, early majority, late majority, and laggards" [2]. Culture affects the rate of adoption of innovation dependent on the personality of the key adopters and their decision making policies.
Five attributes were identified by Rogers [1,2] (1995) that affected the rate of adoption of an innovation, these being the innovation's: "relative advantage, compatibility, complexity, trialability and observability". His basis for deriving these five attributes were on historic writing and research with the need for maximal conciseness and generality.

The next significant advance to Roger's theory of diffusion were the work of Tornatzky and Klein [4] in 1982 with their contribution of a further 25 more attributes, viz.:

"Association with major enterprise", "Clarity of results", "Communicability", "Continuing Cost", "Cost", "Divisibility", "Ease of operation", "Flexibility", "Importance", "Initial Cost", "Mechanical attraction", "Payoff", "Pervasiveness", "Profitability", "Radicalness", "Rate of cost recovery", "Regularity of reward", "Reliability", "Riskiness", "Specificity of evaluation", "Saving of discomfort", "Saving of time", "Scientific status", "Social approval" and "visibility".

Although, "Pervasiveness" and "Social approval" have been considered, other parameters of cross-cultural aspects have been completely ignored.

Reference [5] identified that "complexity" is the most used innovation attribute in the Diffusion of Innovation (DOI) theory.

\section{DIFFUSION OF INNOVATION THEORY}

Roger's Diffusion of Innovation Theory (DOI), ranks as one of the oldest in the social sciences. Its origin lies in explaining how ideas and products propagate in time through the fabric of human society and the factors that contribute to it. The outcome is the eventual adoption of the technology, idea or product by society. A change in the behavioural action must accrue from this novel adoption that makes diffusion or spread of the idea or product feasible. 
Adoption of an idea and more specifically the theme of the paper, "innovation" - does not occur simultaneously. It is adopted by select people with unique characteristics from the population norm. Thus to make the innovation appeal to a wider target audience, their profile needs to be known beforehand. This will ensure a more effective promotion of the technology amongst them.

Five categories of adopters exist with the majority population being in the middle category. Understanding which category the target population lies in will determine what strategy to employ in order to maximize adoption of the innovation. The five categories, which are shown in Fig. 1, are, viz.:

i) Innovators: these are the pioneer adopters of the technology. These people like novelty and are commonly risk takers and also innovative themselves. The people in this target group need little convincing and are the easiest to target.

ii) Early Adopters: this group of people are generally the strategic leaders and are acutely aware of the need to change. They are thus very amenable to adopting innovative changes and technologies. Often times they like to indulge themselves in do it yourself activities with the aid of 'how to do it yourself' manuals. They require little information to adopt innovation.

iii) Early Majority: these are the people who whilst not being leaders themselves like to embrace innovation. They do, however, need to be presented with clear evidence of the benefit of adopting the innovative product or idea. Thus, evidence, that shows effectiveness of the innovation and success stories will likely appeal to them.

iv) Late Majority: these are the skeptics of the population. They will only take on the innovation after the majority. To appeal to this late majority, they need to be convinced about how the others have successfully embraced the innovation before them and have clearly benefitted from it and continue to do so.

v) Laggards: these are the traditionalists, skeptics and conservatives. They are resistant to change and the hardest to convince. To appeal to them, they need to be presented with statistics, peer pressure from the other groups and even 'fear appeals'.

For an effective spread or diffusion of the innovation there are four stages in which this takes place. This consists of the:

i) awareness of the innovation, which is key in the diffusion of the innovation to actually take place;

ii) decision to whether to embrace the innovation or to reject it; iii) use of the innovation initially in order to test it and finally,

iv) continuation of the use of the novel innovative technology.

For each of the five target population classes, there also exist five factors that exert an influence in the adoption of the innovative technology. These being:

i) Relative Advantage - the extent to which the innovation is seen to offer an advantage over the contemporaneous instrument it is replacing.

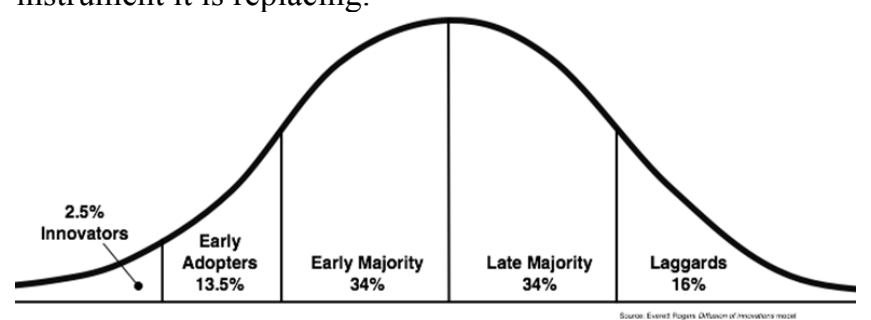

Figure 1. The five categories of innovation adopters of a population.

ii) Compatibility - how does the innovation blend or integrate with the current product or idea in terms of the user experience, values and needs.

iii) Complexity - the innovation should not be overly complex with a steep learning curve, which would then act as a detractor to its implementation.

iv) Triability - the innovation must be easily testable and also deployable, so that the initial assessment of it can be carried out before a final decision is made to whether to adopt it or not.

v) Observability - the innovation must be seen to produce concrete and observable results by the subject.

Research is ongoing with many major organisations working on long term projects involving a consortium of universities [6]. Mathematical models have also been applied to better model, predict and analyse the diffusion patterns of innovation. Integrating observed historical behaviour with mathematical modelling is still an ongoing research project. Initial results show that internal influences were an overriding factor for innovation adoption [7]. Several decades of theories and empirical data exist $[1,2,3,8]$, however.

Today's economies [9] are based on information processing. Business firms in order to remain competitive have to always adopt innovative technologies [10].

Casting new Information Technology (IT) as organizational innovation [11], the information system (IS) researchers have investigated the diffusion and adoption of modern software 
practice [12,13], spreadsheet software [14], customer-based inter-organizational systems [15], database management systems [16], electronic data interchange [17], and IT in general [18]. These investigations concentrate on innovation attributes and factors that predict adoption behaviour. This is an area that is the primary focus of many contemporary innovation researchers [4].

Lately IS innovation researchers have focused on integrating IS innovation with general innovation theories. An example being Swanson's tri-core theory [19] which extends Daft's [20] dual-core theory of technical and administrative innovation in organizations by amalgamating IS innovation, that constitute the third core. The research of Grover, Fiedler, and Teng [21] provides partial empirical support for Swanson's theory.

Mathematical modeling of different types of organization innovation shows the existence of a statistical bell shaped curve for the frequency of adoption plotted against time. Also a general S-shaped curve is exhibited when cumulative number of adopters are plotted [22,23]. Initially the adoption rate is very low with only a minimal number of social systems adopting innovation. However, the rate of adoption then increases rapidly till the familiar bell-shaped peak curve is arrived at. Then the rate of innovation adoption decreases. The curve then show that the adoption spreads asymptotically to saturation level, where the maximal level of adopters is attained. This is the point where diffusion is complete.

Variations of this 'S-curve' behaviour does exist for diffusion models for the different types of innovations [22,24]. The principal model used include the: internal logistic curve influence model, the internal influence model and the Gompertz function and the Bass model [24,25].

\section{CROSS-CUltural ASPECTS OF TECHNOLOGY DIFFUSION}

Although no formal theories have been proposed yet, Miraz et al. $[26,27,28,29,30,31]$ have been extensively working on the cross-cultural aspects of technology diffusion and adoption trends. Cross-cultural Usability, as part of Universal Usability, is another aspect of their research. They have rightly pointed out the existing cultural and socio-economic barriers to the adoption and diffusion of technologies, especially for Information System (IS) and suggested probable solutions.

Extensive studies [26] of web interfaces have shown that they have to be modified to appeal to different cultural predilections. Particular consideration should be given to the choice of colour, layout, design and the language used with respect to the cultural and religious norms of the target population. Since many IT products incorporate a graphical interface, they should take the findings of [26] into consideration to help the product be adopted by various nations. It is should be noted, that often the language used to describe the product, its design and colour can have a profound effect overriding the technical functionality of the object itself. Something as innocuous as the colour of the object may have a different significances to different nations. How some of these factors have been applied to a mobile learning platform for students can be found in [27]. The consideration of the user's background in terms of technical competency should always be taken into account at the same time without being condescending. Aligning Digital Media Technologies with Non-Western Linguistic and Cultural Sensitivities are also addressed in [28]. The use of the right font and making the interface ambidextrous are important factors when marketing cultures where both left-to-right and right-to-left written scripts are in use, not overlooking that vertically written scripts may also be used. As more and more of the non-English world is opened up to newer technologies by the English speaking producing nations, it is imperative to give equal importance to its non-English products [29]. As the study of [29] found that the English version had more time spent on its design over the non-English version. This bias can be very harmful for the concerned company, ruining its reputation irreversibly. The diffusion of mobile broadband technology devices was covered in the study of [30]. The comparison between Bangladesh and Britain found that user behaviour was different for Bangladeshis favouring email access whereas British users preferred plain texting as one example. Thus devices need to appeal to the different technological needs of different nations with the multifunctional capabilities to do so. The case of modesty and gender in displaying information was addressed in [31]. What may be acceptable in one society may not be so acceptable in another. Technology should be seen as an enabler and facilitator of a task and not as an antagonistic device to be banned from society when seen or perceived as a social evil.

\section{Cross-Cultural ASPECtS of TeChNOlOGY ADOPTION}

A clear understanding of the cultural impact of diffusion on IT is necessary to stem and reverse the high failure rate of many innovations in the marketplace. Superior technology does not always gain acceptance amongst consumers, a classic example being the demise of the superior Betamax and Video2000 videocassette formats over the VHS (video home system) tape format. Clear marketing and understanding of the populace is necessary. [32] states the need to study "the influence of lead users on accelerating diffusion rate", in order to successfully accelerate the rate of diffusion of the technical product. Opinion leaders also need to be identified in every culture and society, as often they are the earliest adopters of the technology Often they spread the benefit of the new technology by word of mouth - this means of communication 
though primitive and anachronistic is what actually helps in exerting influence globally in the spread of technology. The spread of information in praise of the new product follows a hierarchical flow throughout human society. [32] further states that the lead user should be involved in the product development stage to the final product design stage in order to expedite the innovation diffusion. Furthermore the innovation has to be accepted by the society before the actual innovation diffusion can take place. The economic status of the country also needs to be considered for the innovative product not to be seen as a luxury item. [32] concluded that innovation diffusion does spread more rapidly in "individualistic cultures" over "collectivist cultures", however, the opposite is the case with innovation acceptance. In difficult markets the role of key players to influence the decision of the consumer is key, often where uncertainty avoidance prevails in the marketplace and the culture of the society. Virtual communities can be exploited further in societies with a high level of internet penetration and this needs to be taken into account when globally marketing the innovative product.

\section{CONCLUSIONS}

For effective adoption of innovation, the characteristics of the target population should be taken into account in order to effectively appeal to them. This is especially so for the late adopters and skeptics who require a more planned evidence based case to be presented to them.

There is still much scope for development in the mathematical modeling of diffusion of innovation theory and in the refinement of the existing models. Sensitive adherence to culture is key in opening of those more reserved societies to new innovative technologies.

The study undertaken was limited in scope to just over fifty papers which were published in exclusively high impact journals. This does preclude many papers which may have covered many exotic and niche applications. These niche applications have the potential to one day become common applications. Thus it is important to keep this study constantly updated with a broader scope of literature review. This will be our future work.

For the rapid dissemination of any technological product it must feel natural to the user, wherever that person is in this world. That is the main conclusion of the various research conducted and from the surveys elucidated.

\section{REFERENCES}

[1] Everett M. Rogers, Diffusion of Innovations, 1st ed. Glencoe, Illinois, USA: Free Press, 1962.

[2] Everett M. Rogers, Diffusion of Innovations, 5th ed. New York, USA: Simon \& Schuster, Inc., 2003.

[3] Everett M. Rogers and Floyd F. Shoemaker, Communication of Innovations; A Cross-Cultural Approach, 2nd ed. Glencoe, Illinois,
USA: Free Press, 1971, Revised Edition of Diffusion of Innovations.

[4] Louis G. Tornatzky and Katherine J. Klein, "Innovation Characteristics and Innovation Adoption-Implementation: A Meta-Analysis of Findings," IEEE Transactions on Engineering Management, vol. 29, no. 1, pp. 28 - 45, February 1982. [Online]. http://ieeexplore.ieee.org/xpl/articleDetails.jsp?arnumber $=6447463$

[5] Kawaljeet Kaur Kapoor, Michael D. Williams, Yogesh K. Dwivedi, and Banita Lal, "An Analysis of Existing Publications to Explore the use of the Diffusion of Innovations Theory and Innovation Attributes," in Proccedings of The World Congress on Information and Communication Technologies (WICT 2011), Mumbai, India, 11-14 December, 2011, pp. 229 - 234. [Online].

http://ieeexplore.ieee.org/xpl/articleDetails.jsp?arnumber=6141249

[6] Catherine E. Brawner, Robert C. Serow, James Demery, and Carl F. Zorowski, "Impact, Institutionalization and Innovation Diffusion: An Evaluation of the SUCCEED Coalition," in Proceedings of The 29th ASEE/IEEE Fronticrs in Education Conference (FIE '99), vol. 3, San Juan, Puerto Rico, 10-13 November, 1999, pp. 13C1/25 - 13C1/29. [Online].

http://ieeexplore.ieee.org/xpl/articleDetails.jsp?arnumber $=840418$

[7] James T. C. Teng, Varun Grover, and Wolfgang Güttler, "Information Technology Innovations: General Diffusion Patterns and Its Relationships to Innovation Characteristics," IEEE Transactions on Engineering Management, vol. 49, no. 1, pp. 13 - 27, August 2002. [Online].

http://ieeexplore.ieee.org/xpl/articleDetails.jsp?arnumber $=985744$

[8] Fariborz Damanpour, "Organizational Innovation: A Meta-Analysis of Effects of Determinants and Moderators," The Academy of Management Journal, vol. 34, no. 3, pp. 555-590, September 1991. [Online]. http://www.jstor.org/stable/256406

[9] Peter F. Drucker, "Knowledge-Worker Productivity: The Biggest Challenge," California Management Review, vol. 41, no. 2, pp. 79-94, 1999. [Online].

http://www.forschungsnetzwerk.at/downloadpub/knowledge_workers the biggest challenge.pdf

[10] Michael E. Porter and Victor E. Millar, "How Information Gives You Competitive Advantage," Harvard Business Review, vol. 63, no. 4, pp. 149-160, July - August 1985. [Online]. https://hbr.org/1985/07/howinformation-gives-you-competitive-advantage

[11] James L. McKenney and F. Warren McFarlan, "The Information Archipelago-Maps and Bridges," Harvard Business Review, vol. 60, pp. 109-119, September - October 1982. [Online]. https://hbr.org/1982/09/the-information-archipelago-maps-andbridges/ar/pr

[12] Robert W. Zmud, "Diffusion of Modern Software Practices: Influence of Centralization and Formalization," Management Science, vol. 28, no. 12, pp. 1421 - 1431, December 1982. [Online]. http://pubsonline.informs.org/doi/abs/10.1287/mnsc.28.12.1421

[13] Robert W. Zmud, "The Effectiveness of External Information Channels in Facilitating Innovation within Software Development Groups," MIS Quarterly, vol. 7, no. 2, pp. 43-58, June 1983. [Online]. http://www.jstor.org/stable/248912 
[14] James C. Brancheau and James C. Wetherbe, "The Adoption of Spreadsheet Software: Testing Innovation Diffusion Theory in the Context of End-User Computing," Information Systems Research, vol. 1, no. 2, pp. 115-143, June 1990. [Online]. http://www.jstor.org/stable/23010618

[15] Varun Grover, "An Empirically Derived Model for the Adoption of Customer-based Interorganizational Systems," Decision Sciences, vol. 24, no. 3, pp. 603-640, June 1993. [Online]. http://onlinelibrary.wiley.com/doi/10.1111/j.15405915.1993.tb01295.x/abstract

[16] Varun Grover and James T.C. Teng, "An examination of DBMS adoption and success in American organizations," Information \& Management, vol. 23, no. 5, pp. 239-248, November 1992. [Online]. http://www.sciencedirect.com/science/article/pii/037872069290055K

[17] K. Ramamurthy and G. Premkumar, "Determinants and Outcomes of Electronic Data Interchange Diffusion," IEEE Transactions on Engineering Management, vol. 42, no. 4, pp. 332-351, August 2002. [Online]. http://ieeexplore.ieee.org/xpl/articleDetails.jsp?arnumber=482083

[18] Vincent S. Lai and Jan L. Guynes, "An Assessment of the Influence of Organizational Characteristics on Information Technology Adoption Decision: A Discriminative Approach," IEEE Transactions on Engineering Management, vol. 44, no. 2, pp. 146-157, May 1997. [Online].

http://ieeexplore.ieee.org/xpl/articleDetails.jsp?arnumber $=584923$

[19] E. Burton Swanson, "Information Systems Innovation Among Organizations," Management Science, vol. 40, no. 9, pp. 1069-1092, September 1994. [Online].

http://pubsonline.informs.org/doi/abs/10.1287/mnsc.40.9.1069

[20] Richard L. Daft, "A Dual-Core Model of Organizational Innovation," The Academy of Management Journal, vol. 21, no. 2, pp. 193-210, June 1978. [Online]. http://www.jstor.org/stable/255754

[21] Varun Grover, Kirk D. Fiedler, and James T. C. Teng, "Empirical Evidence on Swanson's Tri-Core Model of Information Systems Innovation," Information Systems Research (ISR), vol. 8, no. 3, pp. 273-287, September 1997. [Online]. http://pubsonline.informs.org/doi/abs/10.1287/isre.8.3.273

[22] Uma Kumar and Vinod Kumar, "Technological Innovation Diffusion: The Proliferation of Substitution Models and Easing the User's Dilemma," IEEE Transactions on Engineering Management, vol. 39, no. 2, pp. 158 - 168, August 2002. [Online]. http://ieeexplore.ieee.org/xpl/articleDetails.jsp?arnumber $=141273$

[23] Vijay Mahajan and Robert A. Peterson, Models for Innovation Diffusion, 1st ed. Newbury Park, CA, USA: SAGE Publications, Inc, 1 May 1985.
[24] Nigel Meade and Towhidul Islam, "Technological ForecastingModel Selection, Model Stability, and Combining Models," Management Science, vol. 44, no. 8, pp. 1115-1130, August 1998. [Online]. http://www.jstor.org/stable/2634690

[25] Frank M. Bass, "A New Product Growth for Model Consumer Durables," Management Science, vol. 15, no. 5, pp. 215 - 227, January 1969. [Online].

http://pubsonline.informs.org/doi/abs/10.1287/mnsc.15.5.215

[26] Mahdi H. Miraz, Peter S. Excell, and Maaruf Ali, "User Interface (UI) Design Issues for Multilingual Users: A Case Study," International Journal of Universal Access in the Information Society (UAIS), December 2014. [Online].

http://link.springer.com/article/10.1007\%2Fs10209-014-0397-5

[27] Mahdi H. Miraz, Sajid Khan, Moniruzzaman Bhuiyan, and Peter Excell, "Mobile Academy: A Ubiquitous Mobile Learning (mLearning) Platform," in Proceedings of the International Conference on eBusiness, eCommerce, eManagement, eLearning and eGovernance (IC5E 2014), University of Greenwich, London, UK, 30-31 July, 2014, pp. 89-95. [Online]. http://edlib.asdf.res.in/2014/ic5e/ic5e2014014.pdf

[28] Mahdi H. Miraz, Peter Excell, and Maaruf Ali, "Aligning Digital Media Technologies with Non-Western Linguistic and Cultural Sensitivities," in Glynd $\hat{w} r$ University \& Staffordshire University Joint Researcher Development Conference, Wrexham, United Kingdom, 28th May 2014.

[29] Mahdi H. Miraz, Maaruf Ali, and Peter Excell, "MULTILINGUAL WEBSITE USABILITY ANALYSIS BASED ON AN INTERNATIONAL USER SURVEY," in the proceeding of the fourth international conferences on Internet Technologies and Applications (ITA 13), Wrexham, United Kingdom, 2013, pp. 236-244.

[30] Mahdi H. Miraz, Monir Bhuiyan, and Md. Emran Hossain, "IMPACTS OF CULTURE AND SOCIE-ECONOMIC CIRCUMSTANCES ON USERS' BEHAVIOR AND MOBILE BROADBAND TECHNOLOGY DIFFUSION TRENDS," in the proceedings of the Fourth International Conference on Internet Technologies and Applications (ITA 11), Wrexham, UK, 2011, pp. 473-479.

[31] Mukhtar M. Rana, Mahdi H. Miraz, Mohammed Fakrudeen, and Harima Mubeen, "Cross-Cultural Information System Issues and Users' Behaviour: A Case Study in the KSA," in Proceedings of the 6th IASTED International Conference on Human Computer Interaction (HCI 2011), Washington, DC, USA, 2011, pp. 1-6. [Online]. http://www.actapress.com/PaperInfo.aspx?paperId=451917

[32] Ahmed H. Tolba, Maha Mourad, "Individual and cultural factors affecting diffusion of innovation", J. of Int. Business and Cultural Studies, p.1-16, http://www.aabri.com/manuscripts/11806.pdf 